\title{
ПРОБЛЕМЫ ФОРМИРОВАНИЯ МЕДИАКУЛЬТУРЫ СТУДЕНТОВ РОССИИ
}

\author{
Г. А. Ткачев \\ Российский экономический университет им. Г. В. Плеханова
}

Аннотация: Информационные и медиа-технологии становятся неизбежной частью жизни у людей, профессия которых вынуждает работать в медиа-среде, но, помимо этого, она становится элементом досуга у людей различных социальных групп. В связи с этим растет необходимость компетентности при работе с современными информационными технологиями для обеспечения безопасности личных данных.

Текст доклада автора на XV Международной научной конференции «Высшее образование для XXI века. Роль гуманитарного образования в контексте технологических и социокультурных изменений», которая прошла 14-16 ноября 2019 года в Московском гуманитарном университете.

Ключевые слова: медиаграмотность, медиакультура, образовательный процесс, СМИ

\section{THE ISSUES OF MEDIA CULTURE DEVELOPMENT AMONG RUSSIAN STUDENTS}

\author{
G. A. Tkachev \\ Plekhanov Russian University of Economics
}

\begin{abstract}
Information and media technologies are becoming inevitable in the life of people whose profession determines their engagement in the media sphere; on top of that, they are becoming part of leisure activities of people belonging to various social groups. In this connection, there is a growing need for competency when working with modern information technologies in order to ensure the security of personal data.

The text of the author's speech at the 15th International Scientific Conference "Higher Education for the 21st Century. The Role of Education in Humanities in the Contest of Technological and Sociocultural Changes" held at Moscow University for the Humanities on 14-16 November 2019.

Keywords: media literacy; media culture; education process; mass media
\end{abstract}

Проблема компетентности человека в процессе обработки информации становится актуальной в связи с научно-техническим прогрессом и модернизацией средств коммуникации в информационном обществе.

Современное общество называют информационным, поскольку в постиндустриальную эпоху возросло количество информации и ее влияние на все сферы жизни общества. Ф. Уобстер писал: «не удается установить, каким образом информация заняла центральное место в обществе, она настолько 
Научные труды Московского гуманитарного университета 2020 № 1

важна, что даже стала фактором создания общества нового типа» (Уэбстер, 2004: 14).

Среда обитания человека интерсекциональна. Ее составляют профессия человека, его интересы, место жительства, политические предпочтения. Разные потоки информации воздействуют на реципиента и являются фактором его дальнейшего целеполагания, мотивации и деятельности.

Сегодняшний человек обладает неограниченными объемами информации благодаря сети Интернет. К этому стоит добавить, что все чаще люди пользуются Интернетом через смартфоны. Если в 2014 г. доля пользователей интернетом через смартфоны была на уровне 26\%, то в 2019 г. число увеличилось до 48\%. Это значит, что доступ к любой информации возможен моментально, благодаря гаджетам. Россиянин сегодня проводит в Интернете 6 часов 29 минут в сутки, что является средним по миру показателем, практически идентичным показателю США (6 часов 31 минута) ${ }^{1}$.

Одним из главных трендов как в мире, так и в России является цифровизация.

Медиакультура - совокупность материальных и интеллектуальных ценностей в области медиа, а также исторически определенная система их воспроизводства и функционирования в социуме. По отношению к аудитории «медиакультура» может выступать «системой уровней развития личности человека, способного воспринимать, анализировать, оценивать медиатекст, заниматься медиатворчеством, усваивать новые знания в области СМИ.

Усложнившийся мир требует все больше информации для своего функционирования. Изначально, данную ситуацию назвали «инфорационным взрывом». Однако, данный термин закрепился давно, аще в 60-70-х годах прошлого века. Теперь потоки информации постоянно стремительно увеличивается, причем этот процесс носит стабильный устойчивый характер (Пронина, 2008).

Увеличение объемов информации стимулирует новый процесс - цифровизацию. В узком смысле цифровизация определяется как преобразование информации в цифровую форму, которое в большинстве случаев ведет к снижению издержек, появлению новых возможностей и т. д. В широком смысле данный процесс определяется как тренд эффективного мирового развития, в том случае, если цифровая трансформация информации отвечает следующим требованиям: она охватывает производство, бизнес, науку, социальную сферу; сопровождается эффективным использованием ее

${ }^{1}$ Тенденции монетизации контента в Интернете. Медиапотребление в России - 2019. [Электр. peсурс] // Deloitte. URL: https://www2.deloitte.com/ru/ru/pages/technologymedia-and-telecommunications/articles/media-consumption-in-russia.html (дата обращения 10.10.2019). 
результатов; ее результаты доступны пользователям преобразованной информации; пользователи цифровой информации имеют навыки работы с ней (Халин, Чернов, 2018). В связи с этим даже правительство Российской Федерации стало реагировать на глобальных процесс. Основываясь на определении медиаграмотности, принятом Министерством связи и массовых коммуникаций РФ, обновленные параметры медиаграмотного поведения были отнесены к пяти видам компетенций:

1. Умение эффективно искать и находить необходимую информацию;

2. Умение обезопасить себя от вредоносного и избыточного контента;

3. Умение верифицировать и критически оценивать информацию с использованием альтернативных источников информации;

4. Способность адекватно воспринимать информацию и эффективно (грамотно) ее использовать;

5. Умение эффективно и корректно распространять информацию с учётом требований законодательства (защита персональных данных, авторских прав, противодействие экстремизму и пр.).

Данные требования к работе с информацией объективно уместны. К тому же с увеличением объемов информации, обрабатываемых жителем информационного общества, важность компетенций при обработке информации повышается.

Интересен пример, демонстрирующий влияние медиа на поведение реципиентов. В 1994 г. в результате конфликта между хуту и тутси, завершившегося геноцидом тутси, погибло до 20\% населения, или до 1000000 человек. Интересно, что самые массовые убийства происходили на юге Руанды, и именно на юге старны качество покрытия радиостанциями было выше. Исследование Оксфордского журнала показало, чем выше качество вещания было в регионе, и чем ниже уровень грамотности населения, тем более жестоким оказывалось насилие в сторону тутси ${ }^{1}$.

Новости, встречающиеся читателю зачастую ассиметричны, противоречивы. Трактовка одного события будет разительно отличаться, в зависимости от того, кто информацию о событии распространяет. Во избежание противоречивости информации, а также когнитивного диссонанса, реципиент выбирает каналы коммуникации, которые кажутся ему более объективными, и, в дальнейшем оказывается лоялен именно ранее выбранным каналам. Автором теории когнитивного диссонанса является Л. Фестингер, он определял когнитивный диссонанс как, «конфликтные ситуации, возникающие в когнитивной структуре одного человека» (цит. по: Андреева, 2005: 126). Естественно данное противоречие чаще всего решается в пользу

\footnotetext{
${ }^{1}$ Oxford Academic. Propaganda and Conflict: Evidence from the Rwandan Genocide. [Электр. pecypc] URL: https://academic.oup.com/qje/article-abstract/129/4/1947/1853091?redir ectedFrom=fulltext (дата обращения 05.06.2019)
} 
Научные труды Московского гуманитарного университета 2020 № 1

выбора принятия одного суждения при отрицании противоположного.

Медиа аналитики еще в XX веке писали о сложности работы с информацией.

Вот некоторые из тезисов, применяемых канадскими преподавателями при анализе медиапродуктов.

1. Все медиаматериалы сконструированы;

2. СМИ конструируют действительность;

3. Аудитория предопределяет содержание медиасообщений;

4. СМИ преследуют коммерческие цели;

5. СМИ идеологизированы и проповедуют те или иные ценности;

6. СМИ преследуют социальные и политические цели;

7. В СМИ форма и содержание взаимосвязаны;

8. Каждый вид СМИ имеет уникальную эстетическую формуㄷ․

Для оценки медиаграмотности следует, для начала, оценить структуру медиапотребления. Поскольку эффективность работы с информации зависит от источников коммуникации. Все критерии медиаграмотности, артикулированные Министерством и перечисленные выше, зависят именно от источников информации, используемых обществом, будь то умение эффективно искать необходимую информацию или умение верифицировать и критически оценивать информацию с использованием альтернативных источников информации. В России существует разделение сегмента телевизионных СМИ и Интернет-СМИ. Для аргументации данного тезиса возможно использование опросов ФОМа и ВЦИОМа, однако, с точки зрения автора, они менее репрезентативны. К тому же менее детализированны, чем исследования международных организаций. Международная сеть компаний Deloitte Touche Tohmatsu, входящая в «большую четверку» в своей области, занимается консалтингом и аудитом, однако в сферу деятельности Deloitte входит аналитика и исследования экономики, процесса цифрофизации в различный странах мира. Согласно исследованию за 2019 г., Интернет обошел телевидение по уровню доверия населения ${ }^{2} .78 \%$ россиян получают информацию из интернета и 42\% доверяют Интернету как источнику информации. Для сравнения телевидению доверяют 28\% респондентов, для 58\% населения телевидения является главным источником информации. Все большую популярность набирают интернет-медиа. Главное отличие Интернет каналов от телевидения - это относительный плюрализм мнений.

\footnotetext{
${ }^{1}$ Уинг К. (2004) Что такое интернет-грамотность. Справочник по свободе массовой информации в Интернете [Электр. ресурc] URL: https://www.osce.org/ru/ fom/13849?download=true C. 169.

2 Тенденции монетизации контента в Интернете. Медиапотребление в России. [Электр. pecypc]// Deloitte. URL: https://www2.deloitte.com/ru/ru/pages/technologymedia-and-telecommunications/articles/media-consumption-in-russia.html (дата обращения 10.10.2019)
} 
Телеканалы освещают новости с позиции действующей власти, акционерами каналов числятся «Газпром-Медиа холдинг», «Росимущество», бизнесмены, входящие в число близкого окружения президента России В. В. Путина. Социальные сети долгое время составляли альтернативную повестку, но в последнее время появился Telegram. Несмотря на неудавшиеся попытки со стороны государства заблокировать месседжер, со временем свои каналы открыли В. Соловьев, М. Симоньян, О. Скабеева и другие телеведущие, работающие на федеральных каналах. В социальной сети «ВКонтакте» увеличилось количество рекламы действующей власти. Особенно это было заметно в связи с выборами мэра Москвы, на которых и был избран С. С. Собянин.

Таким образом, можно констатировать, что аудитории Интернет-каналов и телеканалов начинают пересекаться.

Аудитория телевизионных СМИ как правило старше, более лояльна к власти и медиаграмотность у нее ниже. Аудитория Интернет СМИ моложе, менее лояльна власти, при этом с более высоким уровнем медиаграмотности. Как показало исследование спецпроекта Аналитического центра НАФИ «Цифровая грамотность для экономики будущего», медиаграмотность населения России растет с каждым годом, однако, чем моложе человек, тем выше уровень его компетенций. Например, согласно проеденному опросу, 35\% людей возраста 18-24 не подвергают полученную информацию сомнению, среди населения возраста 45-54 лет процент составляет уже 53\%. О сложности работы с информацией в возрасте 18-24 лет заявили только 13\%, в возрасте 45-54 лет - 22\%. Помимо этого, чем старше человек, тем сложнее ему осваивать новые технологии, тем меньше он прислушивается к позиции собеседника ${ }^{1}$.

Сегодня устраивается множество мероприятий по повышению медиаграмотности в России, и та территории СНГ. Для повышения медиаграмотности обычно задействуют конференции, семинары и лекции. Например, в Беларуси 16-18 октября 2019 г. прошел масштабный форум «Media Literacy Solutions»². На него приглашали: 1) журналистов и других медиапрофессионалов 2) работников образования (формального и неформального, для детей и взрослых); 3) представителей общественных организаций, инициатив, проектов. Спикерами форума были специалисты по медиакоммуникации из США и Европы, сотрудники Google, IREX, даже лауреат Пулитцеровской премии, Аарон Шарокман. Интересным является тот факт, что приглашаются на форум представители профессий, которые связаны с соз-

\footnotetext{
${ }^{1}$ Исследовательский спецпроект Аналитического центра НАФИ «Цифровая грамотность для экономики будущего». [Электр. pecypc] URL: https://www.nafi.ru/analytics/ tsifrovaya-gramotnost/ (дата обращения: 08.10.2019).

${ }^{2}$ Media Literacy Solutions. (2019) [Электр. pecypc] URL: http://medialiteracy.digital/rus (дата обращения: 08.10.2019).
} 
данием и конструированием информации, т. е. работники общественных организаций, журналисты, учителя. То есть форум нацелен на повышение компетенций не реципиентов, но именно коммуникаторов. Именно коммуникаторы в свою очередь, повысив качество обработки и распространения информации, смогут изменить коммуникативную культуру потребителей медиа информации. Учителя в дальнейшем смогут задействовать полученные знания в процессе обучения школьников.

Также, уже в России, действует проект Гёте-института “The Earth Is Flat - How to Read Media?" С сайта университета можно узнать, что «проект надеется объединить усилия экспертов и педагогов, теоретиков и практиков медиа для создания эффективных методов повышения медиаграмотности. Он будет обращаться к опыту специалистов из России и Германии, которые давно занимаются этой темой, а также пробовать и распространять новые форматы и подходы» ${ }^{1}$. Преимущество данного проекта состоит в том, что он предоставляет гранты участникам, организовывает лекции со специалистами в области медиа, а также публикует статьи на тему медиаграмотности, например, как защититься от кибербуллинга или синдрома $\mathrm{FOMO}^{2}$.

Следует сказать, что медиаграмотность естественным образом повышается от поколения к поколению, поскольку более молодые люди больше пользуются новыми технологиями и в процессе их освоения, навыки медиапользователей растут.

Тем не менее, высшим учебным заведениям следует заняться мониторингом крупных мероприятий, информировать студентов о грядущих лекциях, семинарах. Также с помощью данных мероприятий возможно повышение компетенций преподавателей, которые в процессе образования, будут учить студентов качественной обработке информации, доносить специфику процесса массовой коммуникации сегодня, опираясь на тезисы признанных миром теоретиков медиа.

\section{СПИСОК ЛИТЕРАТУРЫ}

Уэбстер, Ф. (2004) Теория информационного общества / под. ред. Е. Л. Вартановой. М. : Аспект Пресс. 400 с.

Пронина, Л. А. (2008) Информация, информационное общество и человек [Электр. ресурс] // Аналитика культурологии. URL: http://www.analiculturolog.ru/ (дата обращения 05.10.2019)

Халин, В. Г., Чернова, Г. В. (2018) Цифровизация и ее влияние на рос-

\footnotetext{
1 "The Earth Is Flat — How to Read Media?" [Электр. pecypc] URL: https://howtoreadmedia. ru/ru/what_is_media/read/ (дата обращения: 13.10.2019).

${ }^{2}$ Оксфордский словарь. Lexico. Definition of FOMO in English [Электр. pecypc] URL: https://www.lexico.com/en/definition/fomo (дата обращения: 13.10.2019).
} 
сийскую экономику и общество: преимущества, вызовы, угрозы и риски // Управленческое консультирование. № 10.

Андреева Г. М. (2005) Психология социального познания : учеб. пособие для студентов вузов. 3-е изд., перераб. и доп. М.: Аспект Пресс. 303 с.

Дата поступления: 10.10.2019 2.

Ткачев Георгий Андреевич - студент факультета экономики и права Российского экономического университета им. Плеханова, , по направлению политология. Адрес: 143006, Россия, г. Одинцово, ул. Белорусская, д. 9, кв. 51. Тел.: +7 (977) 670-70-17. Эл. адрес: egor-tkachev-97@mail.ru

Tkachev Georgiy Andreyevich, Student, Faculty of Economics and Law, Plekhanov Russian University of Economics, academic programme «Politology". Postal address: 9, Apt. 51, Belorusskaya St., Odintsovo, Russian Federation, 143006. Tel.: +7 (977) 670-70-17. E-mail: egor-tkachev-97@mail.ru

\section{Для цитирования:}

Ткачев Г. А. Проблемы формирования медиакультуры студентов России [Электронный ресурс] // Научные труды Московского гуманитарного университета. 2020. № 1. URL: http://journals.mosgu.ru/trudy/article/view/1124 (дата обращения: дд.мм.гг.). DOI: 10.17805/trudy.2020.1.5 